\title{
Does cat attachment have an effect on human health? A comparison between owners and volunteers
}

\author{
Filipa Alexandra Benchimol da Silva Garcia Dinis and Thaís Lima Fernandes Martins ${ }^{1}$
}

Abstract

Cat owners and volunteers from a rehoming centre were given the Lexington Attachment to Pet Scale (LAPS) questionnaire to assess their level of attachment to their own or rescue cats. In addition, heart rate and blood pressure were measured 10 minutes before, during, and after spending time with the cats. Consistent with other studies, the results here show that spending time with a cat can reduce heart rate and both systolic and diastolic blood pressure, and that this reduction is generally more pronounced in the cats' owners rather than in volunteers from a cat rehoming centre. For owners, levels of attachment as measured by the LAPS scale were positively associated with this reduction in metabolic measurements before and during pet presence; i.e. the difference (B-D) was positively correlated with the level of attachment. This was not observed for volunteers. Interestingly, however, reported levels of attachment were not significantly different between owners and volunteers. For owners, duration of ownership had a positive effect on the level of attachment reported and this effect increased sharply after two plus years of ownership. This contribution to Human Animal Interaction (HAI) research suggests that attachment is an important factor in promoting health benefits to owners.

\section{HIGHLIGHTS}

Physiological responses are reported before, during and after cat presence

The effect of reported levels of attachment for both owners and volunteers is investigated

Pet Behaviour Science | 2016, Vol. 1, 1 - 12

Filipa Alexandra Benchimol da Silva Garcia Dinis

Thaís Lima Fernandes Martins

1. Cornwall College Newquay. Centre for Applied Zoology

Paper Research

Email:

thais.martins@cornwall.ac.uk

TR7 2LZ

United Kingdom
Keywords:

attachment, companion animals, cat, human-animal interaction (HAI), human health
The importance of pet ownership for health benefits, particularly long-term ownership, is highlighted

Questions about the possible effect of the combined effect of home and ownership in providing health benefits are raised

\section{INTRODUCTION}

There is a growing scientific interest across a range of disciplines in the relationship between pets and humans, which is often referred to as Human Animal Interaction (HAI). There is growing evidence of benefit in particular when related to physical and psychological effects (reviews in Chur-Hansen et al. 2010; Arhant-Sudhir et al. 2011; Beetz et al. 2012). Owning a pet is associated with reduced stress (e.g. Allen et al. 1991; Allen et al. 2002; Beetz et al. 2011), lower salivary cortisol (e.g. Beetz et al. 2011), lower heart rate and blood pressure (e.g. Nagengast et al. 1997; Demello 1999), and improved self-esteem (e.g. McNicholas et al. 2005). Reductions in stress seem to involve reduction in activity in the central autonomic nervous system (Allen et al 1991; Arhant-Sudhir et al. 
2011), probably mediated by the oxytocin system (Handlin et al. 2011; Beetz 2012).

Pets are usually chosen on the basis of their ability to respond in an affiliative manner (Schuelke et al. 1992) and they are perceived as friends which are nonjudgmental, loyal, and fond of their owners (Allen 2003; Turner et al. 2003; Cavanaugh et al. 2008; Smolkovic et al. 2012). However, physiological effects on humans from owning a pet can be influenced by psychological, physical, and social measures in a complex way (Wood et al. 2005). For example, the level of human-pet attachment has been mostly ignored or under-valued as most studies investigating physiological effects have failed to report it (review in Beetz 2012). One exception was the study by Vormbrock and Grossberg (1988) where attachment towards companion animals was associated with lower mean arterial pressure and systolic blood pressure. Attachment is reported more often in studies of mental health benefits because pet owners who are closer to their pets feel less lonely and are more sociable (Walsh 2009; Herzog 2011).

Beetz et al. (2012) reviewed 69 studies on HAI between 1983 and 2011. Several of these studies investigated the effects of HAI on the cardiovascular system and reported reductions in blood pressure and heart rate in the presence of a pet such as a dog, particularly during demanding tasks (Demello 1999; Arhant-Sudhir et al. 2011; Beetz et al. 2012). Other research has shown that petting or talking to a dog is correlated with a significant decrease in blood pressure and heart rate in both owners and pets (Allen et al. 1991), as well as better survival rates after myocardial failure (Allen et al. 2002; Wells 2009; 2011). However, no effects of companion animal have also been found in relation to blood pressure and heart rate measurements as exemplified by Straatman et al. (1997) and Hansen et al. (1999).

Only a few studies in the field of HAI focused on cats (Allen et al. 2002; Beetz 2012). However, the cat population in the UK alone is approximately 8.5 million. Therefore, it is important to include research on the effects of cats and not just dogs. Furthermore, a large portion of the studies were conducted in a laboratory environment. However, such environments are not likely to be conducive to observing normal behaviours. For example, in order to encourage natural behaviour, Merola et al. (2015), in his laboratory experiment, used only cats that were accustomed to changes in their living environment. Wells (2011) reported some conflicting research results on cats as physiological benefits from interactions were not always present (e.g. Friedmann and Thomas 1995, reported cat owners more likely to die of a heart attack than non-cat owners), highlighting the need for more studies on this pet species as human-cat relationship are known to be functional and mutually beneficial. For example, cats behaved sensitively to human depressive moods and engaged in more allorubbing of the head and flank (Rieger and Turner 1999), approached owners who described themselves as feeling numb less often, and approached owners who felt extroverted or agitated more frequently (Turner and Rieger 2001, review in Vitale Shreve and Udell 2015). Cats can also change their behaviour towards an object in line with the emotional message given by the owner (Merola et al. 2015) and show a number of attachment behaviours including physical contact, allorubbing, playing, and vocalising with the owner (Vitale Shreve and Udell 2015). In addition, cats have been shown to alleviate negative moods and this effect was comparable to the effect of a human partner (Turner et al 2003).

Health depends on various aspects of a person's lifestyle: dog ownership is known to be one of them (Wood et al. 2005) as this has been linked to more exercise (Wells 2011). In addition, the confounding effect of better health associated with dog walking (Serpell 1991, Wood et al. 2005, Wells 2011) is not a factor when studying cats and so studies on cats are more likely to detect any health benefits associated with pet ownership alone.

This study contributes to an on-going discussion on HAI and is concerned with the effect of levels of attachment between pet and owner as a possible underlying cause of cardiovascular health benefit (Winefield et al. 2008; Wells 2009) and well-being (Crawford et al. 2006). This study focused on whether level of attachment affects physiological measures such as heart rate and blood pressure in the presence and absence of the cat. This study compares the impacts on cat owners with that on volunteers in a cat rescue centre. The attachment bond formed with one's own pet should promote stronger physiological responses (Schuelke et al. 1992; Julius et al. 2013). Since research has already shown that pet owners gain greater health benefits from their own pets compared to people who use animals as a method of therapy (Allen et al. 2002), it is predicted that owners petting their own cat will gain greater short term relaxation, measured through blood pressure and heart rate, than volunteers. Among pet owners, it is predicted that higher levels of attachment will correspond with greater decreases in 
blood pressure and heart rate. This study contributes to HAI research by assessing the effects of cats on human health and thus has implications for healthcare and the promotion of well-being.

\section{METHODS}

\section{Questionnaire}

The Lexington Attachment to Pets Scale (LAPS, Johnson et al. 1992) was used in this study to measure the level of emotional comfort in the owners' relationships to their cats. This scale consists of 23 items but 2 items ('I think my pet is just a pet' and 'I am not very attached to my pet') were excluded as they were somewhat negative questions and had the potential to cause offence (BPS 2014). Answers were provided on a 4 -point scale ( $1=$ strongly disagree to $4=$ strongly agree; Zasloff 1996). Therefore possible scores ranged from 23 to 92 with the highest scores representing a higher level of attachment (see Appendix 1). Participants were given the questionnaire upon acceptance of participation and prior to the beginning of the experiment.

\section{Measurement of Blood Pressure and Heart Rate}

The Omron M2 classic upper arm blood pressure monitor was used to measure blood pressure (systolic and diastolic). Pressure was measured in millimetres of mercury $(\mathrm{mmHg})$ and heart rate $(\mathrm{HR})$ in beats per minute (bpm) taken at the upper left arm, before, during, and after the presence of the cat. This was a non-invasive technique and fully automatic.

\section{Participants}

Participants (age 18+) in this study were recruited across Cornwall. Cat owners who agreed to participate $(\mathrm{n}=20)$ completed a questionnaire, the Lexington Attachment to Pets Scale (LAPS, Appendix 1) to establish their level of attachment with their cat. The sample of owners included people aged 18 to 64 $($ mean $=34.58$, se $=3.39)$.

The same questionnaire was used to assess the level of attachment with volunteers at the Cats Protection League Centre in Truro, UK $(n=20)$. The sample included people between the ages of 18 and 65 (mean=41.87, se= 3.86). There was no significant difference between the two groups in terms of age ( $\mathrm{t}$ test, $\mathrm{t}=-1.41, \mathrm{df}=38, \mathrm{p}=0.16$ ) but to correct for any effect of age on the physiological measurements, age was included in the data analysis (see section 2.6.).
None of the participants in this study had previous problems with hypertension, were on any related medication or were smokers. Due to participants' commitments, sessions were run mostly on weekends.

\section{Experimental Setting}

To provide cat owners and cats with familiar surroundings and to encourage the most natural behaviour from both cat and owner, measurements were taken at the owner's residence. The living room was the room used in all cases since this is the room where normally the owner and cat most frequently interact. All electronic devices were turned off to avoid disturbances which could have had an effect on the measurements taken.

For volunteers, all measurements were taken at the volunteer's common room in the Cats Protection League Centre in Truro, UK, and all measurements for 'during' cat presence were carried out in the cat's pen a few steps away from the common room.

\section{Procedure}

Upon arrival at each participant's home, informed consent and the completed questionnaire were collected. The cat was removed from the room for this procedure. In the absence of the cat, the participant was free to rest and sit quietly in the room for a period of 10 minutes to allow for blood pressure and heart rate to stabilize at baseline level. At the end of next 10 minutes (20 min into the session), measurements were taken of blood pressure (systolic and diastolic, $\mathrm{mmHg}$ ) and heart rate (bpm). The left arm was always used for more accurate measurements. These measurements were called 'before' in the data analysis. The cat was then welcomed into the room and no attempt was made to constrain the cat's movements or actions. Most cats did seek attention from the owner, who remained seated. The cat often remained with the owner during the next measurements which were taken after 10 minutes of the cat's presence (30 min into the session). This measurement was called 'during'. The cat was then removed from the room by the experimenter and after 10 mins of the cat's absence (40 min into the session); measurements were taken again and called 'after'. In all cases, the researcher (FD) sat on the left hand side for ease of measurement and all measurements were taken by FD.

Upon arrival at the cat rescue centre, informed consent and the completed questionnaire were collected. The volunteer was free to rest and sit quietly in the common room for a period of 10 minutes. Blood 
pressure and heart rate measurements were taken at the end of the next 10 minutes ('before'), on the left arm for accurate results. The volunteer then went to the cat pen a few steps away, rested again for 10 minutes (on a chair placed outside) and then entered the pen. Again there was no restriction on the cat's movements or actions. Most cats would show interaction and play with volunteers. After 10 minutes the volunteer would exit the pen, sit on the chair, and blood pressure and heart rate were measured again; this measurement was called 'during'. The volunteer would return to the common room and after 10 minutes, blood pressure and heart rate would be measured again termed 'after'). In all cases, FD sat on the left hand side of the volunteer in the common room and outside the cat's pen and carried out all the measurements.

\section{Statistical Analysis}

\section{Repeated measures}

Data were analysed using the General Linear Mixed Models, GEE (repeated measures) procedure in SPSS (version 21). Data on HR, Systolic and Diastolic pressure were tested for normality and once the distribution was identified the appropriate link function was applied to transform the data. The distribution of the data was identified in all cases as being 'Inversed Gaussian' and therefore 'log link function' was used. Models included the type of participant (owner or volunteer), time of measurement (before, during and after), the interaction between the two and age of participant as a covariate because age is an important factor in blood pressure (Lewington et al. 2002). Analyses that were found to be significant were then analysed further with the least significant variables removed using a stepwise deletion process, prior to repeating the analysis. This was repeated for main effects and interactions; however if the interaction was significant no main effects were removed. Age remained in the model even if not significant, to control for possible physiological differences due to age (Lewington et al. 2002).

\section{The LAPS score: level of attachment}

The difference between physiological measurements before cat and during cat presence (B-D) was used to assess the effect of level of attachment in both owners and volunteers. The differences (B-D) for HR, Systolic and Diastolic pressure were tested for normality and data for owners was normal (Shapiro-Wilk test, all $\mathrm{p}>0.05$ ) but the data for volunteers was not (all $\mathrm{p}<0.05$ ). However, the data distribution for level of attachment for owners was identified as not normal (Shapiro-Wilk test, all $\mathrm{p}<0.05$ ) and therefore GLMMs (Inversed Gaussian, log link) were carried out between B-D differences and level of attachment for both owners and volunteers. In all cases the analyses were carried out using B-D for HR, Systolic and Diastolic as response and level of attachment as predictor (covariate). However, for volunteer B-D differences, the data had to be made positive by the addition of 15 (as some differences were negative (up to -14) and 'log link function' does not accept negative numbers). The figures show the data without this addition.

The importance of years of ownership on the level of attachment was explored given that this predictor has been reported elsewhere as being a factor in the LAPS scores of levels of attachment (Cavanaugh et al. 2008). As length of ownership was not normal (Shapiro-Wilk test, $\mathrm{p}=0.049$ ), a GLMM (inversed Gaussian, log-link function) was carried out between level of attachment and time of ownership (years), with the latter defined as a covariate.

\section{RESULTS}

\section{Physiological Measurements}

Heart rate was significantly different over time (Fig 1a, $\chi^{2}=27.74, \mathrm{df}=2, \mathrm{p}<0.001$ ), and it reduced during the cats' presence in relation to before and after. No significant effect of type of participant was detected $\left(\chi^{2}=3.34, \mathrm{df}=1\right.$, $\mathrm{p}=0.07)$; however the interaction term was significant, showing that owners and volunteers reacted differently to the experiment $\left(\chi^{2}=29.59, \mathrm{df}=2, \mathrm{p}<0.001\right)$, with owners showing a decrease and a corresponding increase in the sequence B-D-A, with volunteers remaining the same. Age of participant was not significant $\left(\chi^{2}=2.64, \mathrm{df}=1, \mathrm{p}=0.10\right)$.

Systolic blood pressure was significantly different over time (Fig 1b, $\chi^{2}=27.06, \mathrm{df}=2, \mathrm{p}<0.001$ ), although participant type was not a significant factor $\left(\chi^{2}=1.04\right.$, $\mathrm{df}=1, \mathrm{p}=0.31)$, showing that both volunteers and owners reacted in the same way. There was no significant interaction term indicating that the decrease was the same in both groups and this term was therefore removed from the model. The covariate participant age, however, was significant $\left(\chi^{2}=16.79\right.$, $\mathrm{df}=1, \mathrm{p}<0.001$ ) showing that age was a factor in determining systolic blood pressure.

Diastolic blood pressure was also significantly different over time and like all other physiological parameters, it reduced during and increased after the pet was 
removed from the room (Fig 1c, time: $\chi^{2}=10.99, \mathrm{df}=2$, $\mathrm{p}<0.001$ ), with owners showing a decrease and a corresponding increase in the sequence B-D-A while the level in volunteers remained the same. For diastolic blood pressure there was no significant difference between owners and volunteers (participant: $\chi^{2}=0.03$, $\mathrm{df}=1, \mathrm{p}=0.86$ ) but the interaction term was significant demonstrating that there was a difference in the way owners and volunteers diastolic blood pressure changed over time (interaction term: $\chi^{2}=9.27, \mathrm{df}=2$, $\mathrm{p}=0.01)$. As for systolic pressure, participant age was significant $\left(\chi^{2}=34.02, \mathrm{df}=1, \mathrm{p}<0.001\right)$ indicating that age is also a factor determining diastolic blood pressure.

\section{LAPS Score- The importance of Levels of Attachment}

For owners, there was a positive significant effect of level of attachment on the difference in HR between before and during (B-D: $\chi^{2}=21.09, \mathrm{df}=1, \mathrm{p}<0.001$, see Fig2a). This means that the reduction in HR with the cat present was positively linked to the level of attachment the owner showed towards the pet. The same significant positive effect of level of attachment was present in both Systolic and Diastolic blood pressure (Systolic B-D: $\chi^{2}=27.45, \quad \mathrm{df}=1, \quad \mathrm{p}<0.001$; Diastolic B-D: $\chi^{2}=5.93, \mathrm{df}=1, \mathrm{p}=0.01$, see Fig $2 \mathrm{~b}$ and $2 \mathrm{c}$ ).

For volunteers, reductions in HR, systolic and diastolic blood pressure between before and during the cat's presence were not affected by volunteers' level of attachment to cats at the rescue centre (HR B-D, $\chi^{2}=0.25, \mathrm{df}=1, \mathrm{p}=0.62$; Systolic $\mathrm{B}-\mathrm{D}, \chi^{2}=0.00, \mathrm{df}=1$, $\mathrm{p}=0.96$; Diastolic B-D, $\chi^{2}=0.04, \mathrm{df}=1, \mathrm{p}=0.83$ ). There was no significant difference between owners' and volunteers' level of attachment measured by the LAPS questionnaire (mean score owner $=64.95$, se $=4.96$; mean score volunteer $=61.90, \quad \mathrm{se}=2.07 ; \quad$ Mann-Whitney $\mathrm{U}=137.5, \mathrm{z}=-1.69, \mathrm{p}=0.09$ ).

Level of attachment increased significantly with years of pet ownership for owners (Fig. $3 ; \chi^{2}=9.40, \mathrm{df}=1$, $\mathrm{p}=0.002$ ), showing that the longer owners had the cat, the stronger the LAPS scores in the questionnaire.

\section{DISCUSSION}

Consistent with other studies, the results here show that the presence of a cat or petting a cat can reduce heart rate and both systolic and diastolic blood pressure, and that this reduction is generally more pronounced in the cats' owners rather than in the volunteers from a rehoming centre. For owners, levels of attachment as measured by the LAPS scale were positively associated with this reduction in metabolic measurements before and during pet presence; i.e. the
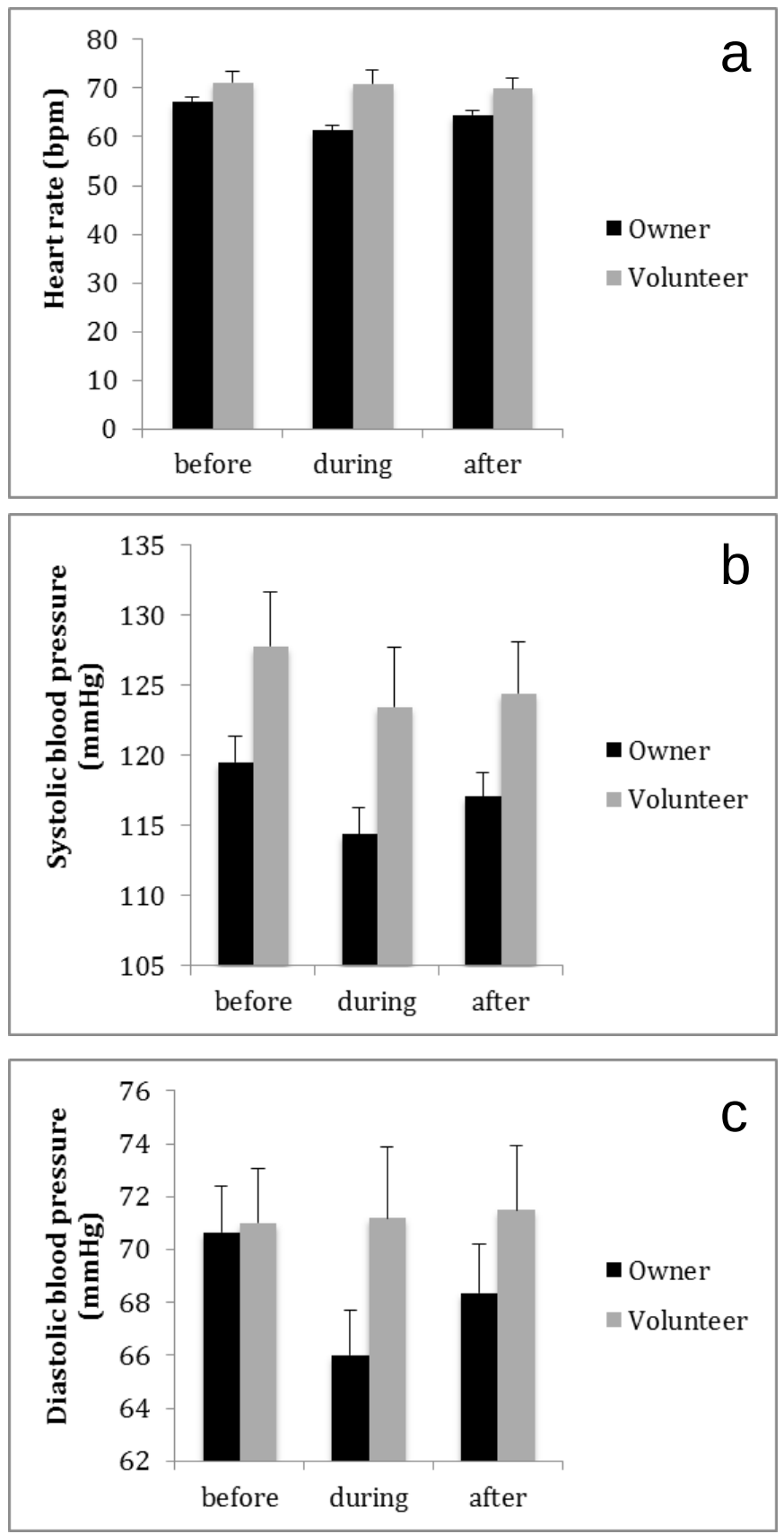

Fig 1. A) Heart rate (bpm), B) Systolic blood pressure (mmHg) and C) Diastolic blood pressure $(\mathrm{mmHg})$ for owners and volunteers before, during, and after exposure to a cat, either their own or from a rehoming centre. For statistical tests see results.

difference (B-D) was positively correlated with the level of attachment. However, interestingly, reported levels of attachment were not significantly different between owners and volunteers. In addition, duration of ownership had a positive effect on the level of attachment reported by owners and this relationship increased sharply after two plus years of ownership. 

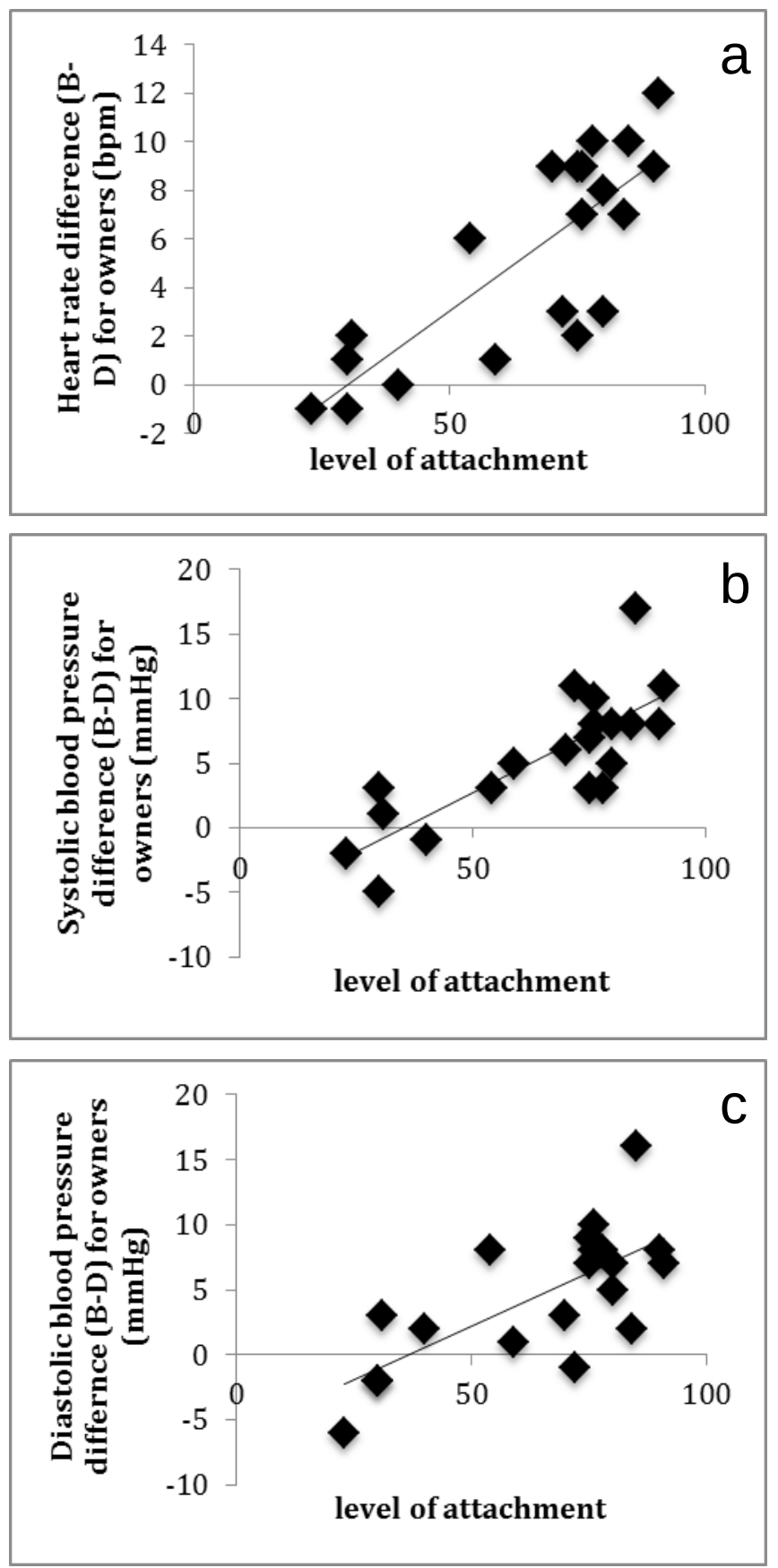

Fig 2. LAPS scores relationship with physiological measurement differences between before and during (B-D) for owners. A) Heart rate $\left.(\mathrm{bpm}), \chi^{2}=21.09, \mathrm{df}=1, \mathrm{p}<0.001 ; \mathrm{B}\right)$ Systolic blood pressure $(\mathrm{mmHg}), \chi^{2}=27.45, \mathrm{df}=1, \mathrm{p}<0.001$; and C) Diastolic blood pressure $(\mathrm{mmHg}), \chi^{2}=5.93, \mathrm{df}=1, \mathrm{p}=0.01$.

The reduction in heart rate and blood pressure in the presence of a pet suggests a health effect particularly for owners. Some studies have reported significant physiological benefits related to pets while others have not (see review in Beetz 2012). Benefits have involved reduction in heart rate (Demello 1999; Handlin et al. 2011) and blood pressure, both arterial and systolic (Grossberg and Alf 1985; Vormbrock and Grossberg 1988), and one study has even shown a significant difference between visual, verbal and tactile experience of pets (e.g. dog, Vormbrock and Gossberf 1988), the latter being significantly more important in reducing blood pressure. The mere presence of a pet, usually a $\mathrm{dog}$, resulted in lower blood pressure and heart rate (Allen et al. 2002; Wells 2009; Beetz et al. 2012). Allen et al. (2002) found presence of a pet to be more effective in reducing blood pressure and heart rate than the presence of a partner and friend. The current study adds to the body of evidence that shows these physiological effects but goes further to suggest that these health benefits are related to the reported level of attachment between owner and cat, which is in turn affected by the length of ownership.

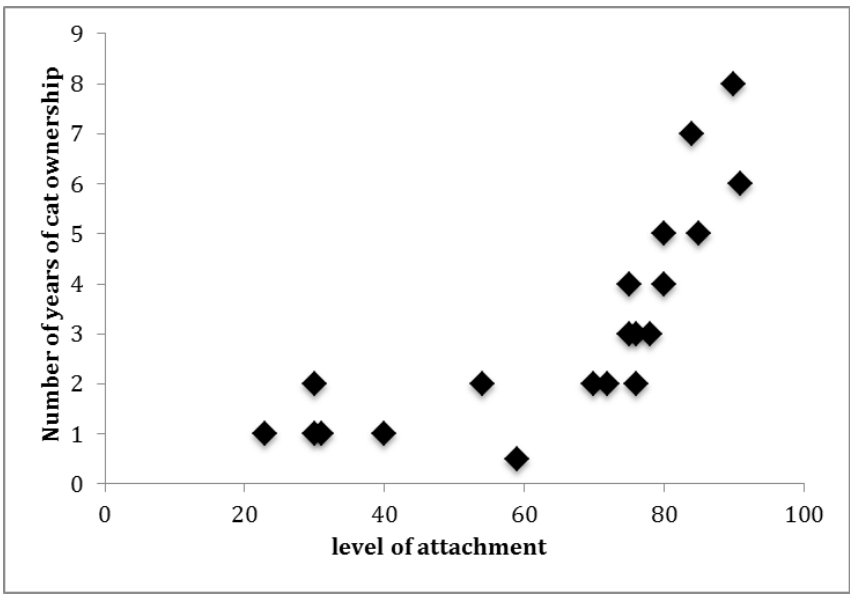

Fig 3. Relationship between level of attachment (LAPS score) and years of cat ownership, showing that the level of attachment increases significantly with duration of ownership, particularly after 3 years $\left(\chi^{2}=9.40, \mathrm{df}=1, \mathrm{p}=0.002\right)$.

The experimental design in this study takes into account several criticisms raised in the field since it compares within individuals, in a before, during and after set-up (Moody et al. 1996), uses cats rather than dogs (as dogs are related to physical exercise, e.g. Friedmann et al. 2003; Arhant-Sudhir et al. 2011 and are therefore known to have a longer term benefit in cardiovascular disease, Wolff and Frishman 2005), and considers physiological parameters taken at home or at the work place rather than in a laboratory environment. In addition, the LAPS attachment scale used here was edited to accommodate the volunteers' responses (e.g. Zasloff 1996) to make it comparable to the owners' reported attachment levels. Other criticisms in this subject area could not be covered in this study (i.e. using people who did not choose to have pets or be around animals, such as in Allen et al. 2001), however, we used two sets of people who liked cats, one that owned cats and one that volunteered at a homing centre. The decision to use two sets of people who showed attachment to cats in this study was preferable; 
given that we wanted to carry out the measurements in a familiar set-up and to use people who did not choose to spend time with cats would create a situation where these 'ordinary' people would be meeting cats in an artificial set-up (such as in a laboratory environment).

Research suggests that owners are just as attached to cats as they are to dogs. Serpell (1996) assessed owner satisfaction with cats a year after re-homing and found that moderately attached owners were not consistently any less satisfied with pets overall than very attached ones. The importance of 'affection' in the cat-owner relationship suggests that simpler behavioural criteria are relevant to cat owner's attachments (Serpell 1996). One possible explanation is that cat behaviour is influenced by characteristics of the human and family, as found by Mertens (1995). A body of evidence supports the notion that cats have developed a range of mechanisms in their interaction with humans (review in Vitale Shreve and Udell 2015). Even though interactions between cats and owners can be overtly operational (i.e. cats can be trained to go for walks and to follow instructions etc.), the humans and cats used in this study did not have an overtly operational relationship. However, human-cat relationships are surely functional in the social sense, for example; cats in households have been shown to be valuable social companions and social supporters (Rieger and Turner 1999, Wedl et al. 2011). Evidence shows that cats are sensitive to human cues such as gaze (Merola et al 2015) and comply with humans intent to interact, with resultant less negative moods in their owners (Turner et al. 2003). The results in this study do suggest that the functionality of people-cat relationship can extend from effects on mood and perceived social support to provision of physiological benefits.

In this study, owners' physiological responses are compared to volunteers' and several differences were found. Volunteers were willing to give their free time to cats and this commitment to animal care was shown in the lack of difference in their reported level of attachment when compared to cat owners. Interestingly, the pet presence effect for volunteers was not strong (even though they also experienced some reduction, particularly in systolic blood pressure) and was not related to the level of reported attachment. It would be expected, however, that levels of self-esteem would be raised by volunteering and increases in selfesteem benefits accrued by a pet have been related to levels of attachment (Triebenbacher 1999, Crawford et al. 2006) but increases in self-esteem have not yet been linked to health benefits. As volunteers' systolic blood pressure was also reduced during cat presence, it is important to conduct further research into this effect.

Owners, as opposed to volunteers, may be more prone to possess personality traits likely to dispose them to enhanced health and well-being (McNicholas and Collins 1998, Wells 2011). However this would have to be assessed in a separate experiment comparing owners to non-owners and volunteers. It can be argued that since volunteers are also 'cat people', the most likely explanation is that it is the presence of a wellknown pet, and staying at home, that results in positive physiological consequences. The use of the common room in the cat homing centre and the pet holding pen (after resting) when measuring volunteers' responses should have yielded similar metabolic changes as owners at home, given that laboratory studies have also shown reductions in physiological measurements when in tactile contact with pets (Allen et al. 2012; Handlin et al. 2011). As measurements on volunteers were always taken after a rest, the different experimental set-up should not have been responsible for the differences between owners and volunteers.

The interesting possibility raised by this study is the combination of both 'family pet and the home environment' that generates the health benefits, and that tactile contact with a cat that is not 'very familiar in the work set-up' yields fewer health benefits. It is important to consider that the effect of a companion animal may be small in comparison to the effect of staying at home (as opposed to going to a shelter), so that the benefit of a companion animal may be additional to the effect of being at home. Wells (2009) also reported greater benefit with familiar animals; however, volunteers are familiar with some cats in the centre and develop companion bonds with certain animals. Further research could concentrate on responses to tactile contact to pets in different set-ups and using cats with which volunteers have special relationships. In addition, Wedl et al. (2011) assessed the interactions between cats and owners and found out that these interactions depended very much on features of the owners not the cat. Perhaps not surprisingly, cats have been shown to be neutral pets that comply with the owners' wishes for some or no interaction (Rieger and Turner 1999). Future studies may concentrate on owners' and volunteers' state (such as self-esteem) as well as attachment.

The possible effect of familiarity of pet and environment for the owner's health suggested here is somewhat reflected in the effect of duration of ownership on the levels of attachment reported by 
owners. It suggests that 'familiarity breeds attachment' as shown in the positive relationship between the duration of ownership and the level of attachment, and the possible physiological impact. The value of a pet has been shown to increase with length of time of ownership (Word 2012) and to be stronger after 3 years (Smolkovic et al. 2012); Cavanaugh et al. (2008) also reported a relationship between well-being and duration of ownership of dogs. The attachment bond created between owner and pet may have implications for how their relationship is maintained over time (Smolkovic et al. 2012). Interestingly, in human relationships, satisfaction tends to decline over time (over the first 4 years) and contributes less to overall well-being (Kurdek 1998).

There has been some interest in the possible mechanisms behind the reported reductions, by many studies, in heart rate and blood pressure. The most likely mechanism is related to cortisol rates mediated by the oxytocin system (Beetz 2012). Oxytocin reduces glucocorticoid levels in humans (Neumann et al. 2000) particularly in relation to social stress (Kirsch et al. 2005). Oxytocin is known to increase in the blood of both humans and dogs after 5 to 24 minutes of stroking a dog (Odental and Meintjes 2003). Salivary cortisol has been measured in dog owners when either petting their own or an unfamiliar dog, or reading a book quietly; both dog treatments reduced cortisol but reading did not (Odendaal 2000; Odendaal and Meintjes 2003). The increase in oxytocin and reduction in cortisol correlated positively with the quality of the relationship, including physical contact. In humans, oxytocin is also linked with human attachment and bonding (Odendaal 2000). In the pet-human situation, the release of oxytocin and reduction in cortisol levels would be expected to be higher in the owner-home combination than in the volunteer-rehoming centre set-up. Another suggested mechanism is a decrease in the central autonomic activity as a consequence of positive mood induction (Arhant-Sudhir et al. 2011), but whichever the possible mechanism, this study suggests that, if positive mood induction is occurring, owners at home are benefiting more than volunteers at a re-home centre. Further studies may concentrate on oxytocin in different people-cat-place combinations.

\section{CONCLUSIONS}

This study suggests that interactions with cats result in positive health benefits for people who enjoy cats. Health benefits were larger the stronger the level of attachment between pet and owner, but the familiarity of home and own pet may be an important factor in these health benefits. For rehoming centre volunteers, the health effects of petting cats were smaller. Further research may focus on pet-cat-place combinations and on the measurement of oxytocin in addition to blood pressure and heart rate.

\section{ACKNOWLEDGEMENTS}

We gratefully acknowledge the permission granted by Libby Luckett, manager of the Truro Cat's Protection League re-homing center and the patience of all participants involved, owners, volunteers and cats. We would also like to thank Dr Kathy Baker from Newquay Zoo for comments on the statistical analysis and to the following people for comments on earlier versions of this manuscript: Roger Kayes, Rebecca Allen, Dr Peter McGregor and two anonymous referees. This manuscript would not have been possible without the support and time for scholarly activity generously given to the corresponding author by Lawrence Moores.

The work described here was carried out in accordance with EU Directive 2010/63/EU for animal experiments and approval for the study was not necessary since animals used in this experiment were allowed to behave normally and were always in their home or holding pen at a UK cat rehoming centre,. Great care was taken during this experiment not to distress the cats in any way. This study has also followed the British Psychological Association guidelines in seeking consent and making sure the questionnaire and the procedures did not cause offence or lasting psychological harm to the human participants.

\section{REFERENCES}

Allen, K. 2003. Are pets a healthy pleasure? The influence of pets on blood pressure. Current directions in Psychological Science 12: 236-239. DOI: 10.1046/j.0963-7214.2003.01269.x

Allen, K. M., Blascovich, J. , Tomara, J. and Kelsey, R. M. 1991. Presence of human friends and pet dogs as moderators of Autonomic responses to stress in women. Journal of Personality and Social Psychology 61: 582-589. DOI: 10.1037/0022-3514.61.4.582

Allen, K., Blascovich, J. and Mendes, W. 2002. Cardiovascular reactivity and the presence of pets, friends, and spouses: the truth about cats and dogs. Psychosomatic Medicine 64: 727-739. DOI: 10.1097/01.PSY.0000024236.11538.41

Allen, K. Shykoff, B. E. and Izzo, J. L. 2001. Pet 
ownership but not ACE inhibitor therapy blunts home blood pressure responses to mental stress. Hypertension 38: 815-820. WOS:000171882300011

Arhant-Sudhir, K., Arhant-Sudhir, R. and Sudhir, K. 2011. Pet ownership and cardiovascular risk reduction: supporting evidence, conflicting data and underlying mechanisms. Clinical and Experimental Pharmacology and Physiology 38: 734-738. DOI: 10.1111/j.14401681.2011.05583.x

Beetz, A., Kotrschal, K. Hediger, K., Turner, D. and Uvnäs-Moberg, K. 2011. The effect of a real dog, toy dog and friendly person on insecurely attached children during a stressful task: an exploratory study. Anthrozoos 24: 349-368. DOI: $10.2752 / 175303711 \times 13159027359746$

Beetz, A., Uvnäs-Moberg, K., Julius, H. and Korschal, K. 2012. Psychosocial and psychophysiological effects of human-animal interactions: The possible role of oxytocin. Frontiers in Psychology 3: 1-15. DOI: 10.3389/fpsyg.2012.00234

BPS. 2014. Code of Human Research Ethics. British Psychological Society, Leicester, UK.

Cavanaugh, L. A., Leonard, H. A and Scammon, D.L. 2008. A tail of two personalities: how canine companions shape relationships and well-being. Journal of Business Research 61: 469-479. DOI: 10.1016/j.jbusres.2007.07.024

Chur-Hansen, A., Stern, C. and Winefield, H. 2010. Gaps in the evidence about companion animals and human health: some suggestions for progress. International Journal of Evidence-Based Healthcare 8: 140-146. DOI:10.1111/j.1744-1609.2010.00176.x

Crawford, E., Worsham, N. and Swinehart, E. 2006. Benefits derived from companion animals, and the use of the term "attachment". Anthrozoos 19: 98-115. DOI: $10.2752 / 089279306785593757$

Demello, L.R. 1999. The effect of the presence of a companion-animal on physiological changes following the termination of cognitive stressors Psychological Health 14: 859-868. DOI: 10.1080/08870449908407352

Friedmann. E. and Thomas, S.A. 1995. Pet ownership, social support, and one year survival after acute myocardial-infarction in the cardiac-arrhythmia suppression trial (CAST). American Journal or Cardiology 76:1213-1217. WOS A1995TK15100001
Friedmann, E. Thomas, S.A., Stein, P.K. and Kleiger, R.E. 2003. Relation between pet ownership and heart rate variability in patients with healed myocardial infarcts. The American Journal of Cardiology 91: 718721. DOI: $10.1016 /$ S0002-9149(02)03412-4

Grossberg, J.M. and Alf, E.F. 1985. Interaction with pet dogs: effects on human cardiovascular response. Journal of the Delta Society 2: 20-27. DOI: $10.1007 /$ BF00844843

Herzog, H. 2011. The impact of pets on human health and psychological well-being: fact, fiction, or hypothesis? Current Direction in Psychological Science 20: 236-239. DOI: $10.1177 / 0963721411415220$

Handlin, L., Hydbring-Sandberg, E., Nilsson ,A., Ejdebäck, M., Jansson, A., and Uvnäs-Moberg, K. 2011. Short-term interaction between dogs and their ownerseffects onoxytocin, cortisol, insulin and heart rate- an exploratory study. Anthrozoos 24: 301-316. DOI: 10.2752/175303711X13045914865385

Hansen, K.M., Messenger, C.J., Baun, M.P. and Megel, M.E. 1999. Companion animals alleviating distress in children. Anthrozoos 12:142-148. WOS:000171726000004

Johnson, T., Garrity, T. and Stallones, L. 1992. Psychometric evaluation of the lexington attachment to pets scale (LAPS). Anthrozoos 5: 160- 175. WOS:A1992JK34700004

Julius, H., Beetz, A., Kotrschal, K., Turner, D. and Uvnas-Moberg, K. 2013. Attachment to pets: an integrative view of human-animal relationships with implications for therapeutic practice. Gottingen: Hogrefe.

Kirsch, P., Esslinger, C., Chen, Q., Mier, D., Lis, S., Siddhanti, S. and Gallhofer, B. 2005. Oxytocin modulates neural circuity for social cognition and fear in humans. Nature 435: 673-676. DOI: 10.1523/JNEUROSCI.3984-05.2005

Kurdek, L.A. 1998. The nature and predictors of the trajectory of change in the marital quality over the first 4 years of marriage for first-married husbands and wives. Journal of Family Psychology 12(4): 494-510. DOI: 10.1037 / / 0012-1649.35.5.1283

Lewington, S.,Clarke, R. Qizilbash, N., Peto, R. and Collins, R. 2002. Age-specific relevance of usual blood pressure to vascular mortality: a meta-analysis of 
individual data for one million adults in 61 prospective studies. The Lancet 360: 1903-1013. WOS:000179870200007

McNicholas, J and Collins, G.M. 1998. Could type A (coronary prone) personality explain the association between pet ownership and health? In: Companion Animals and Human Health, ed. C.C. Wilson and D.C. Turner (Eds.). CA: Sage.

McNicholas, J., Gilbey, A., Rennie, A., Ahmedzai, S., Dono, J.and Ormerod, E. 2005. Pet ownership and human health: a brief review of evidence and issues. British Medical Journal 331: 1252-1255. DOI: 10.1136/bmj.331.7527.1252

Merola, I., Lazzaroni, M., Marshall-Pescini, S., PratoPrevide, E. 2015. Social referencing and cat-human communication. Animal Cognition 18:639-648. DOI: 10.1007/s10071-014-0832-2

Mertens, C. 1995. The human cat relationship. Tierarztliche Umschau 50(2):71-75. WOS:A1995QG74200001

Moody, W., Fenwick, D. and Blackshaw, J. 1996. Pitfalls of studies designed to test the effect pets have on the cardiovascular parameters of their owners in the home situation: a pilot study. Applied Animal Behaviour Science 47: 127-136. DOI: 10.1016/0168-1591(95)01016-5

Nagengast, S. L., Baun, M., Megel, M. M., and Leibowitz, J. M. 1997. The effects of the presence of a companion animal on the physiological arousal and behavioral distress in children during a physical examination. Journal of Paediatric Nursing 12: 323-330. DOI:10.1016/S0882-5963(97)80058-9

Neumann, I.D., Wigger, A., Torner, L., Holsboer, F. and Landgraf, R. 2000. Brain oxytocin inhibits basal and stress-induced activity of the hypothalamo-pituitaryadrenal axis in male and female rats: partial action with the paraventricular nucleus. Journal of Neuroendocrinology 235-243. WOS:000086268400007

Odendaal, J.S.J. 2000. Animal-assisted therapy - magic or medicine? Journal of Psychosomatic Research 48: 275-280. DOI: 10.1016/S0022-3999(00)00183-5

Odendaal, J.S.J. and Meintjes, R.A., 2003. Neurophysiological correlates and affiliative behaviour between humans and dogs. The Veterinary Journal 165: 296-301. DOI: 10.1016/S1090-0233(02)00237-X
Rieger, G., and Turner, D.C. 1999. How depressive moods affect the behaviour of singly living persons towards their cats. Anthrozoos 12:224-233. DOI: $10.2752 / 089279399787000066$

Schuelke, S., Trask, B., Wallace, C., Baun, M., Bergstrom, N. and McCabe, B. 1992. Physiological effects of the use of a companion animal dog as a cue to relaxation in diagnosed hypertensives. The Latham Letter 13: 14-17.

Serpell, J. A. 1991. Beneficial effects of pet ownership on some aspects of human health and behaviour. Journal of the Royal Society of Medicine 84: 717-720.

Serpell, J. A. 1996. Evidence for an association between pet behaviour and owner attachment levels. Applied Animal Behaviour Science 47: 49-60. DOI: 10.1016/0168-1591(95)01010-6

Smolkovic, I., Fajfar, M. and Mlinaric, V. 2012. Attachment to pets and interpersonal relationships. Journal of European Psychology Students 3: 15-24.

Straatman, I., Hanson, E., Endenburg, N. and Mol, J. 1997. The influence of a dog on male students during a stressor. Anthrozoos 10:191-197. WOS:000072492700009

Triebenbacher, S. L. 1999. Re-evaluation of the companion animal bonding scale. Anthrozoos 12: 169173. WOS:000171726000008

Turner, D.C. and Rieger, G. 2001. Singly living people and their cats: a study of human mood and subsequent behaviour. Anthrozoos 14:39-46. WOS:000169910600005

Turner, D.C., Rieger, G. and Gygax, L. 2003. Spouses and cats and their effects on human mood. Anthrozoos 16:213-228. WOS:000220316100002

Vitale Shreve, K.R. and Udell, M.A.R. 2015. What's inside your cat's head? A review of cat (Felis silvestris catus) cognition research past, present and future. Animal Cognition 18:1195-1206. DOI: 10.1007/s10071015-0897-6

Vormbrock, J.K. and Grossberg, J.M. 1988. Cardiovascular effects of human-pet dog interactions. Journal Behavioral Medicine 11: 509-517. DOI: $10.1007 /$ BF00844843

Walsh, F. 2009. Human-animal bonds I: The relational significance of companion animals. Family Process 48: 462-480. WOS:000272128900002 
Wedl, M., Bauer, B., Gracey, D., Grabmayer, C. Spielauer, E., Day, J. and Kotrschal, K. 2011. Factors influencing the temporal patterns of dyadic behaviours and interactions between domestic cats and their owners. Behavioural Processes 86: 58-67. DOI: 10.1016/j.beproc.2010.09.001

Wells, D. 2009. The effects of animals on human health and well-being. The Journal of Social Issues 65: 523-543. WOS:000268271300005

Wells, D. 2011. The value of pets for human health. The psychologist 24: 172-176. WOS:000288476300027

Winefield, H., Black, A. and Chur-Hansen. 2008. Health effects of ownership of and attachment to companion animals in an older population. International Journal of Behavioural Medicine 15: 303-310. DOI: $10.1080 / 10705500802365532$
Wolff, A.I. and Frishman, W.H. 2005. Animal-assisted therapy in cardiovascular disease. Seminars in Integrative Medicine 2: 131-134.

Wood. L., Giles-Corti, B. and Bulsara, M. 2005. The pet connection: pets as a conduit for social capital?. Social Science \& Medicine 61: 1159-1173. DOI: 10.1016/j.socscimed.2005.01.017

Word, J. 2012. Pet perks: an examination and analysis of the relationship between companion animals and the development of empathy. Honors, Texas State University-San Marcos. Texas.

Zasloff, R. 1996. Measuring attachment to companion animals: a dog is not a cat is not a bird. Applied Animal Behaviour Science 47: 43-48. DOI: 10.1016/01681591(95)01009-2 


\section{Appendix I Lexington Attachment to Pets Scale (LAPS)}

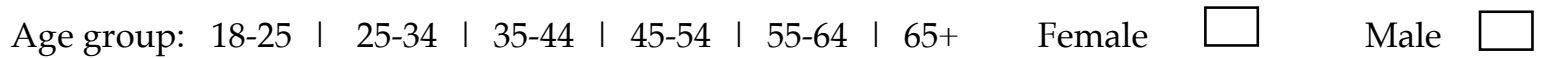 \\ Please state whether you agree or disagree with the following statements about your cat or rescue cat.}

\begin{tabular}{|c|c|c|c|c|}
\hline Circle the one which applies best & $\begin{array}{l}\text { Strongly } \\
\text { Disagree }\end{array}$ & $\begin{array}{l}\text { Somewhat } \\
\text { Disagree }\end{array}$ & $\begin{array}{l}\text { Somewhat } \\
\text { Agree }\end{array}$ & $\begin{array}{c}\text { Strongly } \\
\text { Agree }\end{array}$ \\
\hline \multicolumn{5}{|l|}{$\begin{array}{l}\text { 1. My cat/rescue cat means more to me than any of my } \\
\text { friends. }\end{array}$} \\
\hline 2. Quite often I confide in my cat/ rescue cat. & & & & \\
\hline $\begin{array}{l}\text { 3. I believe that pets should have the same right and } \\
\text { privileges as family members. }\end{array}$ & & & & \\
\hline
\end{tabular}

4. I believe my cat/ rescue cat is my best friend.

5. Quite often, my feelings toward people are affected by the way they react to my cat/ rescue cat.

6. I love my cat/ rescue cat because he/she is more loyal to me than most of the people in my life.

7. I enjoy showing other people pictures of my cat/ rescue cat.

9. I love my cat/ rescue cat because it never judges me

10. My cat/ rescue cat knows when I'm feeling bad.

11. I often talk to other people about my cat/ rescue cat.

12. My cat/ rescue cat understands me.

13. I believe that loving my cat/ rescue cat helps me stay healthy.

14. Pets deserve as much respect as humans do.

15. My cat/ rescue cat and I have a very close relationship.

16. I would do almost anything to take care of my cat/ rescue cat.

17. I play with my cat/ rescue cat quite often.

18. I consider my cat/ rescue cat to be a great companion.

19. My cat/ rescue cat makes me feel happy.

20. I feel that my cat/ rescue cat is a part of my family.

22. Owning a pet / volunteering with pets adds to my happiness.

23. I consider my cat/ rescue cat to be a friend. 